\title{
Evaluation of changes in the growth and chemical constituents of Anoectochilus formosanus Hayata grown under hydroponic conditions
}

\author{
Hoang Chinh Nguyen ${ }^{1}$, Tran Quynh Mong Nhu ${ }^{1}$, Phung Van Dung ${ }^{1}$, Nguyen Dinh Hieu ${ }^{1}$, \\ Tran Trong Tuan ${ }^{2}$, Phan Xuan Huyen ${ }^{3}$, Dieu-Hien Truong ${ }^{1 *}$ \\ ${ }^{1}$ Faculty of Applied Sciences, Ton Duc Thang University, Ho Chi Minh City, Vietnam \\ ${ }^{2}$ Institute of Tropical Biology, Vietnam Academy of Science and Technology, Ho Chi Minh City, Vietnam \\ ${ }^{3}$ Tay Nguyen Institute of Biology, Vietnam Academy of Science and Technology, Da Lat City, Lam Dong, Vietnam
}

\begin{abstract}
Anoectochilus formosanus Hayata is an important medicinal plant with various pharmaceutical properties. In this study, $A$. formosanus plants were hydroponically cultivated in different nutrient solutions to achieve enhanced biomass and secondary metabolites production. Three months-old $A$. formosanus plants were grown for 8 weeks under controlled environment in plastic pots containing Murashige and Skoog (MS), Nitrophoska Foliar (NF), Hydro Green (HG), or Hydro Bee (HB) media. Among 4 nutrient solutions tested, HB was the most efficient medium for the plant growth with the highest fresh weight (FW, $2.56 \mathrm{~g} / \mathrm{plant}$ ) and dry weight (DW, $0.18 \mathrm{~g} / \mathrm{plant})$ values. The results of phytochemical screening showed the presence of alkaloids, flavonoids, terpenoids, glycosides, and steroids in the extracts of $A$. formosanus cultivated in HB, HG, and MS medium. The level of these compounds was significantly different in plants cultivated in tested media. The highest alkaloids $(34.87 \mu \mathrm{g} / \mathrm{g} \mathrm{DW})$ and terpenoids $(56.43 \mu \mathrm{g} / \mathrm{g} \mathrm{DW})$ contents were obtained on HG medium, whereas flavonoids were present in highest amounts $(90.13 \mu \mathrm{g} \mathrm{QE} / \mathrm{g} \mathrm{DW})$ in plants grown in NF medium. On the other hand, HB medium stimulated the production of the highest glycoside $(64.33 \mu \mathrm{g} / \mathrm{g} \mathrm{DW})$ and steroids $(22.83 \mu \mathrm{g} / \mathrm{g} \mathrm{DW})$ levels. The antioxidant activity of the extracts was also tested using the 1,1-Diphenyl-2-picryl-hydrazyl (DPPH) scavenging activity assay and the results demonstrated strong antioxidant activities of $A$. formosanus extracts with $\mathrm{IC}_{50}$ of 136.19 to $248.85 \mu \mathrm{g} / \mathrm{ml}$. Concluding, the hydroponic-cultivation of $A$. formosanus is a promising way for obtaining highly valuable compounds for pharmaceutical and nutraceutical industries.
\end{abstract}

Key words: Anoectochilus formosanus, mineral nutrition, hydroponic conditions, chemical constituents, antioxidant activity

\section{Introduction}

Anoectochilus formosanus Hayata is a terrestrial orchid species of the Orchidaceae family, which is growing mainly in Asia (Tseng et al., 2006; Yang et al., 2017). This is an ornamental plant often called "King medicine”, because of its high pharmacological potential. Its extract possess hepatoprotective (Fang et al., 2008; Cheng and Chang, 2009), anti-diabetic (Rehman et al., 2015), anti-inflammatory (Hsiao et al., 2016), antitumor
(Tseng et al., 2006; Yang et al., 2014; Yang et al., 2017), anti-arthritic (Han et al., 2016), and immunomodulatory activities (Yang et al., 2014; Yang et al., 2017). These pharmaceutical properties are due to the activities of many phytochemicals, including alkaloids, flavonoids, terpenoids, steroids, and their derivatives, which are present in various parts of this plant (Ng et al., 2011; Zhang et al., 2013). A number of biological compounds which showed strong antioxidant activity, eg. glycosides,

\footnotetext{
* Corresponding author: Faculty of Applied Sciences, Ton Duc Thang University, Ho Chi Minh City, Vietnam; e-mail: truongthidieuhien@tdtu.edu.vn
} 
have been found in $A$. formosanus (Du et al., 2000; Wang et al., 2002; Han et al., 2016). Du and coworkers (2000) have isolated megastigma glycosides and butanoic acid glucoside, whereas Wang and coworkers (2002) and Du and coworkers (1998) have identified a kinsenoside and kinsenone, respectively. The antioxidant activities of these compounds are based on scavenging diverse reactive oxygen species (ROS), including peroxyl radicals, hydroxyl radicals, hypochlorous acid, superoxide anions, and peroxynitrite, thus protecting the organism against oxidative damages (Wang et al., 2002; Shih et al., 2003). A. formosanus is therefore considered to be a promising natural source of important and highly valuable metabolite compounds.

The demand of $A$. formosanus is dramatically increasing since the international trade of medicinal plants is becoming a major force in the global economy (Ma et al., 2010; Li et al., 2017). However, the natural source of $A$. formosanus has been significantly reduced due to indiscriminate collection, slow seed germination rate, and slow growth of natural $A$. formosanus plants (Cheng and Chang, 2009; Ma et al., 2010; Zhang et al., 2013). On the other hand, traditional plant growth in soil is burdened by various stress conditions, therefore obtaining the highest quality and quantity of plants for medicinal preparation is often impossible (Ma et al., 2010). From an agricultural viewpoint, plant growth, crop yield and quality are significantly affected by environmental conditions at every growth stage, from seedlings to the harvest (Ma et al., 2010). To conserve and to meet the demands for medicinal plant material, developing new technologies for $A$. formosanus plant production with greater biomass and higher quality is urgently needed.

In recent years, thanks to the advances in tissue culture techniques, large-scale propagation using seedlings and micropropagated plantlets can be achieved (Chang and Chou, 2007; Cheng and Chang, 2009; Wu et al., 2010). Such artificial cultivation techniques have already been employed to establish a rapid propagation system for A. formosanus (Jiang et al., 2015; Ket et al., 2004). Although the use of these techniques for plant cultivation led to some achievements, traditional intensive in vitro culture still has several drawbacks such as low survival rates of transplanted tissue-cultured plantlets, slow growth of plants, long cultivation time (Chang and Chou, 2007; Cheng and Chang, 2009; Jiang et al., 2015). In addition, although tissue culture methods provide a better means to multiple this plant, the metabolic pathways of a plant obtained by tissue cultures may differ from that of the original plant (Huang et al., 1991).

The environmental pollution associated with intensive agriculture has motivated the development of a greenhouse cultivation methods such as closed soilless culture, among which hydroponics is the most widely and frequently used (Molders et al., 2012; Jin et al., 2013; Lin et al., 2013). The method protects plants grown under controlled environment, thus shortening growth cycles and maximizing plant biomass, consistency, and quality (Ma et al., 2010; Molders et al., 2012). Therefore, growing plants under a controlled environment can be considered an alternative way for medicinal plant production to ensure safety and efficacy. In addition to the environmental factors such as temperature, light density, and humidity, the nutrition solutions have remarkable effects on biomass production and biosynthesis of secondary metabolites (Ma et al., 2010; Jin et al., 2013). A number of studies have reported that the balanced nutrient mixture $\left(\mathrm{NH}_{4}, \mathrm{~K}^{+}, \mathrm{Mg}_{2+}, \mathrm{Ca}_{2^{+}}, \mathrm{NO}_{3}\right.$, $\mathrm{H}_{2} \mathrm{PO}_{4+}, \mathrm{SO}_{42}$. can significantly improve growth and alter the concentrations of metabolites (Yoon et al., 2007; Dong et al., 2014). For example, the organic additives such as coconut water or rare earth elements like lanthanum (La), cerium (Ce), and neodymium $(\mathrm{Nd})$ have been reported to have positive effects on plants such as faster growth, higher crop yield, and secondary metabolite compounds levels (Yoon et al., 2007). Recently, Jin and coworkers (2013) reported that a mild iron (Fe)deficient nutrition solution increases the yield and quality of spinach. Therefore, management of mineral nutrient elements in the solution is one of the most important agronomic practices in the hydroponic cultures (Jin et al., 2013). However, there is little information about the effects of nutrients on growth and secondary metabolites of $A$. formosanus. Understanding this effect may help us develop an optimal way of managing nutrient solution in the hydroponic, thus improving the yield and quality of future crops. Therefore, the aim of this study was to investigate the effects of 4 nutrient solutions (Murashige and Skoog (MS, 1962), Nitrophoska Foliar (NF), Hydro Green (HG), and Hydro Bee (HB)) on the growth and secondary metabolite accumulation of hydroponicaly-cultivated $A$. formosanus, under controlled environment. 


\section{Materials and methods}

\section{Plant materials and growth conditions}

Anoectochilus formosanus Hayata plants were obtained from Daklak province, Vietnam. The plants were hydroponically grown in 0.51 plastic container ( 3 plants

Table 1. Composition of nutrient solutions used for hydroponic cultivation of $A$. formosanus

\begin{tabular}{l|c|c|c}
\hline \multirow{2}{*}{$\begin{array}{c}\text { Composition } \\
{[\mathrm{mg} / \mathrm{l}]}\end{array}$} & \multicolumn{3}{c}{ Medium } \\
\cline { 2 - 4 } $\mathrm{N}$ & 25.000 & 7.250 & 6.410 \\
\hline $\mathrm{P}_{2} \mathrm{O}_{5}$ & 10.000 & 4.600 & 3.050 \\
\hline $\mathrm{K}_{2} \mathrm{O}$ & 17.500 & 12.840 & 7.000 \\
\hline $\mathrm{Zn}$ & 0.019 & - & - \\
\hline $\mathrm{Mn}$ & 0.050 & - & - \\
\hline $\mathrm{B}$ & 0.011 & - & - \\
\hline $\mathrm{Cu}$ & 0.019 & - & - \\
\hline $\mathrm{Mo}$ & 0.001 & - & - \\
\hline $2 \mathrm{Fe} \mathrm{NaEDTA}$ & - & - & - \\
\hline $\mathrm{Mg}$ & - & - & - \\
\hline $\mathrm{Ca}$ & - & - & - \\
\hline $\mathrm{Fe}$ & 0.050 & 4.560 & 4.400 \\
\hline
\end{tabular}

NF - Nitrophoska Foliar, HG - Hydro Green, HB - Hydro Bee

per container) filled with different aerated, full-strength complete nutrient solutions. The compositions of nutrient solutions for plant cultivation are as given in Table 1. The $\mathrm{pH}$ and Electrical Conductivity (EC) of these nutrient solutions were daily adjusted to 6.3 and 1.5, respectively, and renewed after 2 weeks. The plants were grown in a greenhouse with a controlled temperature of $22 \pm 2{ }^{\circ} \mathrm{C}$, relative humidity of $75 \%$, and light intensity of approximately $200 \mu \mathrm{mol} \cdot \mathrm{m}^{-2} \cdot \mathrm{s}^{-1}$ provided by fluorescents lamps with a light to dark cycle of $16: 8 \mathrm{~h}$. The whole plants were harvested after 8 weeks to determine the growth and secondary metabolite content. All experiments were set up in triplicate for each treatment.

\section{The growth measurements}

The whole harvested plants including roots, stem, and leaves were measured for their fresh weigh (FW) and dry weight (DW). To measure the dry weight, the plant samples were dried in an oven at $60^{\circ} \mathrm{C}$ until receiving the constant weight.

\section{Preparation of plant extracts and phytochemical screening}

The whole plants were ground with a micromill (Drum Mixer, Hockmeyer) into a powder. To extract the compounds, $1 \mathrm{~g}$ of dry powder was immersed in $10 \mathrm{ml}$ methanol and incubated with stirring for $5 \mathrm{~h}$ at $60^{\circ} \mathrm{C}$. The liquid phase was then separated from the cell debris through filtration using Whatman filter paper No. 4 to obtain the crude extract, then concentrated using a rotary evaporator at a maximum temperature of $60^{\circ} \mathrm{C}$ and freeze-dried for $24 \mathrm{~h}$. All freeze-dried extracts were stored at $4{ }^{\circ} \mathrm{C}$ until further analyses.

The freeze-dried extract was dissolved in absolute $\mathrm{MeOH}(1: 10 \mathrm{w} / \mathrm{v})$. The methanolic Anoectochilus extracts were subjected to phytochemical analysis to screen for the presence of secondary metabolites such as alkaloids, flavonoids, terpenoids, tannins, glycosides, phenolics, saponins, and steroids. The phytochemical screening was carried out using standard procedures (Herborne, 1973; Parekh and Chanda, 2007). The experiments were conducted in triplicate.

\section{Determination of alkaloids, flavonoids, glycosides, tepernoids, and steroids content in plant extracts}

The alkaloids content in the crude methanolic extracts was determined according to the method of Harbone and coworkers (1973). Briefly, $5 \mathrm{~g}$ of dry powder samples were immersed in $200 \mathrm{ml}$ of $10 \%$ acid acetic in ethanol and incubated at $55^{\circ} \mathrm{C}$ for $4 \mathrm{~h}$. The liquid phase was obtained through filtration using Whatman filter paper No. 4 and then concentrated by a rotary evaporator to one-quarter of the original volume. The concentrated $\mathrm{NH}_{4} \mathrm{OH}(25 \%)$ was then added stepwise to the extract until the precipitation was complete. The precipitate was subsequently collected, washed with diluted $\mathrm{NH}_{4} \mathrm{OH}$ (3\%), and filtered using filter paper (Whatman No.1). The precipitate composed of alkaloids was then dried in oven at $60^{\circ} \mathrm{C}$.

Total flavonoids content in the plant extracts was determined following the method of Djeridane and coworkers (2006). One ml of methanol extract was mixed with $1 \mathrm{ml}$ aluminum chloride (2\%). The mixture was stirred and kept at room temperature for $15 \mathrm{~min}$. The absorbance was then measured at $430 \mathrm{~nm}$ using a spectrophotometer (Industrial Area, Panchkula, Haryana). Quercetin (Sigma -Aldrich, Singapore) was used as a reference standard to calculate the flavonoids content. The total flavonoids con- 
tent was expressed as micrograms of quercetin equivalents per gram of dry weight ( $\mu \mathrm{g} \mathrm{QE} / \mathrm{g} \mathrm{DW}$ ).

The glycosides content was measured using the protocol of Steve and coworkers (2016). Briefly, $1 \mathrm{ml}$ of the methanolic extract was mixed with $1 \mathrm{ml}$ of $2 \%$ solution of 3, 5-DNS (di-nitro salicylic acid) in methanol and $1 \mathrm{ml}$ of $5 \%$ aqueous $\mathrm{NaOH}$. The mixture was then boiled for 2 min until the brick-red precipitation was completed. The precipitate was retained through Whatman filter paper No. 4 and dried in an oven at $60^{\circ} \mathrm{C}$, and weighed.

Terpenoids content was determined using a method described by Gulza and coworkers (2017). One g of plant powder sample was mixed with $12 \mathrm{ml}$ ethanol and incubated for $24 \mathrm{~h}$ with stirring. The mixture was filtered through Whatman paper No. 4 and the filtrate was extracted with petroleum ether (Sigma-Aldrich, Singapore). The ether extract was containing total terpenoids, which were then dried by oven at $60^{\circ} \mathrm{C}$ and weighed.

To determine steroids content, $1 \mathrm{~g}$ of dry powder sample was added to $12 \mathrm{ml}$ of ethanol and heated at $80^{\circ} \mathrm{C}$. The mixture was filtered using Wahtman paper No. 4 and the filtrate was mixed with petroleum ether. The ether extract was then dried and weighed to determine the content of steroids.

\section{Determination of the antioxidant activity}

In this study, antioxidant activity of the crude extract and the glycoside extract of $A$. formosanus was determined using the 2,2-Diphenyl-1-picrylhydrazyl (DPPH) free radical-scavenging assay described by Yoshiki and coworkers (2001) with slight modifications. Two mg of glycosides of $A$. formosanus were firstly dissolved in $1 \mathrm{ml}$ absolute methanol to obtain stock solution, then diluted to serial dilutions $(10-1000 \mu \mathrm{g} / \mathrm{ml})$. Aliquots of serial dilutions of $0.05 \mathrm{ml}$ of the extracts were added to $0.15 \mathrm{ml}$ of a DPPH solution (0.4 mM in methanol). Methanol was used instead of a sample as the control. The mixtures were then mixed well and kept in the dark at room temperature for 90 min before measuring the absorbance at $517 \mathrm{~nm}$ using a spectrophotometer (Industrial Area, Panchkula, Haryana). The radical-scavenging activity was calculated using the following equation:

Scavenging activity $(\%)=\left[1-\left(\mathrm{OD}_{1}\right.\right.$ sample $-\mathrm{OD}_{2}$ sample $) /$ $/\left(\mathrm{OD}_{3}\right.$ control $-\mathrm{OD}_{4}$ control $\left.)\right] \times 100 \%$

whereas: $\mathrm{OD}_{1}$ is the absorbance value of sample contained $\mathrm{DPPH}$ in the experimental group, $\mathrm{OD}_{2}$ is the ab- sorbance value of sample did not contain DPPH in the experimental group, $\mathrm{OD}_{3}$ is the absorbance value of control contained DPPH in the control (methanol), $\mathrm{OD}_{4}$ is the absorbance value of control did not contain DPPH in the control (methanol).

A calibration curve was constructed using different concentrations (10-1000 $\mu \mathrm{g} / \mathrm{ml})$ of ascorbic acid, used as a positive control. The concentration required for a $50 \%$ decrease in the absorbance of DPPH radicals $\left(\mathrm{IC}_{50}\right)$ was calculated as the percent of inhibition of DPPH by plotting the percentage of residual DPPH at a steady state as a function of the sample concentration.

\section{Statistical analysis}

Data were determined in triplicate and the results were expressed as the mean \pm standard deviation (SD). All measurements were evaluated for significance by an analysis of variance (ANOVA) with the least significant difference (LSD) test at $P \leq 0.05$ using SAS 9.1 (SAS Institute, Cary, NC, USA).

\section{Results}

\section{Effect of nutrient solutions on the growth of $A$. formosanus}

In this study, 4 nutrient solutions were studied for their effect on the growth of $A$. formosanus. As shown in Figure 1, fresh and dry biomasses of $A$. formosanus cultivated in 4 tested media were significantly different. Among 4 nutrient solutions tested, HB medium was observed to be the most potent for the growth of $A$. formosanus in hydroponic cultivation. The highest fresh and dry biomasses of 2.56 and $0.18 \mathrm{~g} /$ plant, respectively, obtained by cultivating the plant in HB medium, were followed by those obtained in HG medium, and NF medium. MS medium resulted in the lowest growth of A. formosanus with the biomass of $1.02 \mathrm{~g} /$ plant $\mathrm{FW}$ and $0.08 \mathrm{~g} /$ plant DW. These finding suggest that $\mathrm{HB}$ medium is a promising nutrient solution for hydroponic cultivation of $A$. formosanus.

\section{Phytochemical screening}

Secondary metabolites present in A. formosanus cultivated in different nutrient solutions are given in Table 2. Different nutrient solutions used for the plant growth resulted in different composition of various compounds in the extracts. Alkaloids, flavonoids, and glyco- 
A

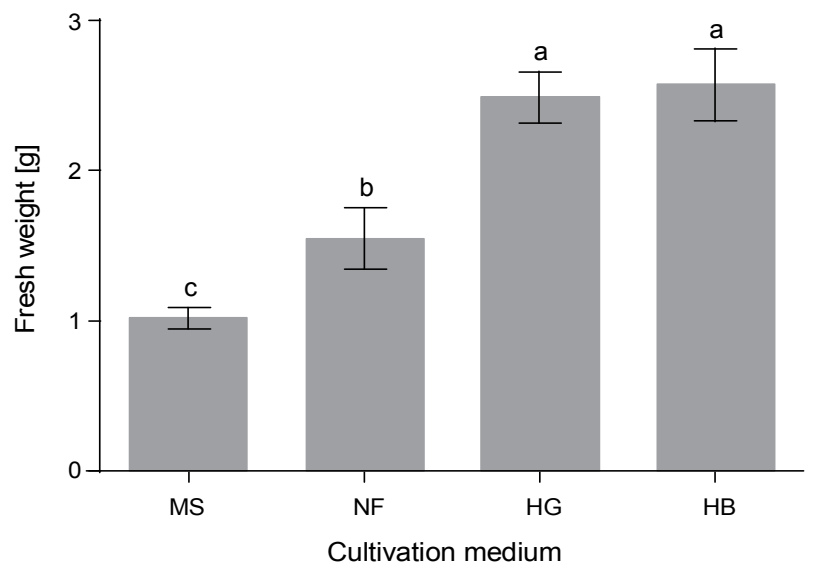

$\mathrm{B}$

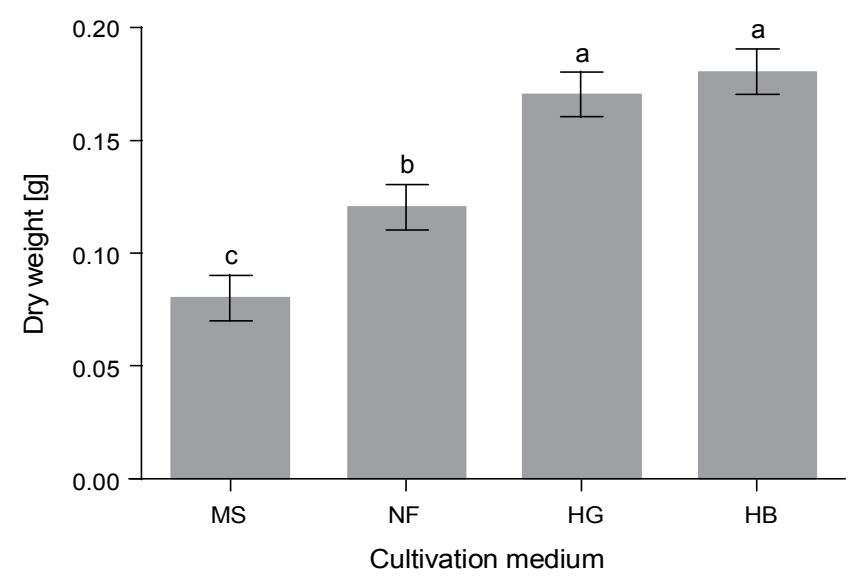

Fig. 1. The production of biomass of $A$. formosanus cultivated in different media

Table 2. Phytochemical constituents of crude extracts of $A$. formosanus cultivated in different media

\begin{tabular}{l|c|c|c|c}
\hline \multirow{2}{*}{ Constituent } & \multicolumn{4}{c}{ Medium } \\
\cline { 2 - 5 } & MS & NF & HG & HB \\
\hline Alkaloids & + & + & + & + \\
\hline Flavonoids & + & + & + & + \\
\hline Terpenoids & + & - & + & + \\
\hline Tannin & - & - & - & - \\
\hline Glycoside & + & + & + & + \\
\hline Phenolic & - & - & - & - \\
\hline Saponin & - & - & - & - \\
\hline Steroids & + & - & + & + \\
\hline
\end{tabular}

MS - Murashige and Skoog, NF - Nitrophoska Foliar, HG - Hydro Green, HB - Hydro Bee, + - presence of secondary metabolite, - - absence of secondary metabolite

sides were observed in all $A$. formosanus extracts. Terpenoids and steroids were found in the extracts of $A$. for- mosanus cultivated in the MS, $\mathrm{HG}$, and $\mathrm{HB}$ medium, but those compounds were absent from the plants cultivated in the NF medium.

\section{The content of secondary metabolite compounds among the plant extracts}

In this experiment, different nutrient solutions were employed to cultivate $A$. formosanus and investigated for their effects on the level of secondary metabolite compounds. The content of alkaloids, flavonoids, glycosides, terpernoids, and steroids in the extracts of $A$. formosanus cultivated in 4 nutrition solutions is presented in Table 3. The level of secondary metabolites varied among nutrient solutions used. The highest level of alkaloids $(34.87 \mu \mathrm{g} / \mathrm{g}$ DW) and terpenoids $(56.43 \mu \mathrm{g} / \mathrm{g} \mathrm{DW})$ were obtained in the extracts of $A$. formosanus cultivated in HG medium, whereas flavonoids reached the highest level of $90.13 \mu \mathrm{g} \mathrm{QE} / \mathrm{g} \mathrm{DW}$ in NF medium. Interestingly, the growth in NF medium resulted in the lowest alkaloids $(17.13 \mu \mathrm{g} / \mathrm{g} \mathrm{DW})$, terpenoids $(0 \mu \mathrm{g} / \mathrm{g} \mathrm{DW})$, and steroids $(0 \mu \mathrm{g} / \mathrm{g} \mathrm{DW})$ contents compared to other media. On the other hand, the extract of $A$. formosanus cultivated in HB medium contained significantly higher levels of glycosides ( $64.33 \mu \mathrm{g} / \mathrm{g}$ DW) and steroids $(22.83 \mu \mathrm{g} / \mathrm{g}$ DW) than in other media. Since the $A$. formosanus growth in HB medium resulted in a high level of secondary metabolite compounds, especially glycosides, it is considered as a potential medium for hydroponic cultivation of $A$. formosanus.

\section{Antioxidant activity}

The antioxidant activities of $A$. formosanus crude extracts and the glycoside extracts cultured in HB medium were measured as DPPH radical-scavenging activity. As shown in Figure 2, different samples possessed different free radical-scavenging activities. The glycoside extract of $A$. formosanus grown in HB medium had significantly higher DPPH radical scavenging activity than the crude extract with the $\mathrm{IC}_{50}$ value of $136.19 \mu \mathrm{g} / \mathrm{ml}$. The glycoside extract demonstrated however lower ability to scavenge $\mathrm{DPPH}$ as compared to ascorbic acid in the same concentration $\left(\mathrm{IC}_{50}=25.56 \mu \mathrm{g} / \mathrm{ml}\right)$.

\section{Discussion}

A. formosanus Hayata is an important medicinal plant, which has been used to treat many diseases including hypertension, cancer, and diabetes mellitus in 
Table 3. Content of alkaloids, flavonoid, glycoside, terpenoids, and steroids in the extracts of $A$. formosanus cultivated in different media

\begin{tabular}{|c|c|c|c|c|c|}
\hline Medium & $\begin{array}{l}\text { Alkaloids } \\
{[\mu \mathrm{g} / \mathrm{g} D W]}\end{array}$ & $\begin{array}{c}\text { Flavonoids } \\
{[\mu \mathrm{g} Q \mathrm{Q} / \mathrm{g} \mathrm{DW}]}\end{array}$ & $\begin{array}{l}\text { Glycoside } \\
{[\mu \mathrm{g} / \mathrm{g} D W]}\end{array}$ & $\begin{array}{l}\text { Terpenoids } \\
{[\mu \mathrm{g} / \mathrm{g} D W]}\end{array}$ & $\begin{array}{l}\text { Steroids } \\
{[\mu \mathrm{g} / \mathrm{g} \mathrm{DW}]}\end{array}$ \\
\hline MS & $22.43 \pm 1.76^{\mathrm{b}}$ & $47.57 \pm 3.38^{d}$ & $34.65 \pm 0.35^{b}$ & $34.27 \pm 0.71^{\mathrm{c}}$ & $12.07 \pm 0.67^{\mathrm{b}}$ \\
\hline $\mathrm{NF}$ & $17.13 \pm 0.51^{\mathrm{c}}$ & $90.13 \pm 1.46^{\mathrm{a}}$ & $31.97 \pm 4.14^{\mathrm{b}}$ & 0.00 & $0.00 \pm 0.00^{\mathrm{d}}$ \\
\hline $\mathrm{HG}$ & $34.87 \pm 2.70^{\mathrm{a}}$ & $65.50 \pm 5.67^{c}$ & $38.17 \pm 3.26^{\mathrm{b}}$ & $56.43^{ \pm} \pm 010.07^{\mathrm{d}}$ & $13.10 \pm 0.75^{b}$ \\
\hline $\mathrm{HB}$ & $20.97 \pm 2.50^{\mathrm{bc}}$ & $75.60 \pm 4.17^{\mathrm{b}}$ & 64.33 & $50.20 \pm 2.45^{\mathrm{b}}$ & $22.83 \pm 0.55^{\mathrm{a}}$ \\
\hline
\end{tabular}

All values are the mean $\pm \mathrm{SD}(n=3)$; means within a column with different letters significantly differ by LSD's test at $P<0.05$

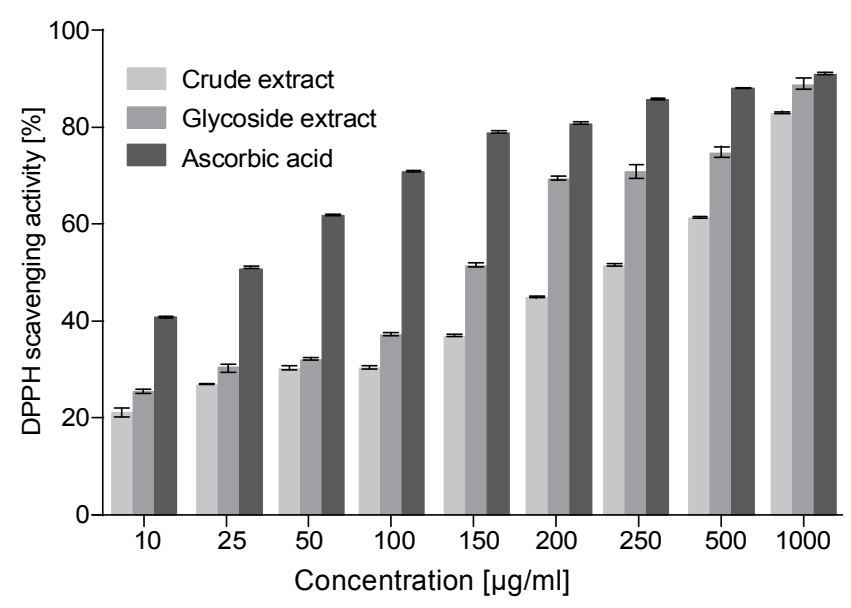

Fig. 2. DPPH-scavenging activities of different extracts of $A$. formosanus compared to the standard (ascorbic acid)

Table 4. The $50 \%$ inhibitory concentration $\left(\mathrm{IC}_{50}\right)$ values of DPPH radical-scavenging activities, of extracts of $A$. formosanus

\begin{tabular}{l|c}
\hline \multicolumn{1}{c|}{ Samples } & $\mathrm{IC}_{50}[\mu \mathrm{g} / \mathrm{ml}]$ \\
\hline Crude extract & $248.85 \pm 1.11^{\mathrm{a}}$ \\
\hline Glycoside-based extract & $136.19 \pm 0.27^{\mathrm{b}}$ \\
\hline Ascorbic acid (control) & $25.56 \pm 1.38^{\mathrm{c}}$ \\
\hline
\end{tabular}

All values are the mean $\pm \mathrm{SD}(n=3)$; means within a column with different letters significantly differ by LSD's test at $P<0.05$

folk medicine in India and Southeast Asia (Tseng et al., 2006; Ng et al., 2011). However, the low preproduction of this plant in the nature and its unlimited collection caused a significant decrease in its population. Therefore, it is necessary to conserve the plants. For further medicinal use it is also crucial to improve its quality. In this study, different nutrient solutions used to hydroponically cultivate $A$. formosanus resulted in wide varia- tions in the growth and chemical constituents of this plant. Among nutrient solutions tested, HB medium was found to be the most efficient for the growth and the production of glycosides and steroids, while HG medium was best suitable for the cultivation of $A$. formosanus to produce alkaloids and terpenoids. This could be caused by the fact that different nutrients present in the medium exert different effects on the growth and the biosynthesis of secondary metabolites (Yoon et al., 2007; Jin et al., 2013). Generally, the nutrients required for normal plant growth in the hydroponic cultures include 6 macronutrients (nitrogen, potassium, magnesium, calcium, phosphorus, and sulfur) and 7 micronutrients (iron, zinc, molybdenum, boron, copper, manganese, and chlorine) (Jin et al., 2013). Among those macronutrients, nitrogen, phosphorus, and potassium are 3 main highly important in the improvement of the crop yield (Jin et al., 2013). In addition to macronutrients, it has been reported that the level of micronutrients also affected the biomass production and chemical constituents of plants in hydroponic-based cultures (Jin et al., 2013). Micronutrients such as iron and zinc are essential for the synthesis of metabolite compounds because they are components of many enzymes associated with the energy transfer, nitrogen reduction and fixation, and lignin formation (Luo et al., 2012; Yadavalli et al., 2012; Jin et al., 2013). The deficiency or excess of micronutrients significantly reduce plant biomass and secondary metabolite production (Luo et al., 2012; Jin et al., 2013). Jin and coworkers (2013) reported that high or low levels of iron in the nutrient solutions strongly decrease the yield and the quality of hydroponic-cultivated spinach. Shafeek and coworkers (2014) reported that micronutrients such as zinc and manganese improve the crop yield and chemical constituents of hot pepper. 
Those micronutrients activate a number of enzymes involved in carbohydrate metabolism and are essential for the functioning of photosynthetic apparatus. Moreover, the micronutrients at optimal levels can also facilitate plants to acquire more macronutrients, thus further improve crop yield (Jin et al., 2013). Therefore, management of macronutrients and micronutrients to obtain a balanced nutrient mixture is the most important issue in the hydroponic cultures, which helps improve the growth and the quality of plants. From that point of view, the highest production of biomass and secondary metabolite compounds of plants grown in HB medium could be a result of an optimal nutrient mixture for the growth and synthesis of metabolites of $A$. formosanus.

There is an increasing interest in using plants as functional foods and nutraceutical products with high antioxidant properties (Brewer, 2011). The wild and in vitro based tissue cultures of $A$. formosanus were previously reported to be the sources of antioxidants (Yoon et al., 2007; Chang, 2009). In this study, the antioxidant activities of hydroponic-cultivated $A$. formosanus were studied using DPPH-scavenging activity assays since free radical scavenging is one of the mechanisms by which antioxidants inhibit lipid oxidation and prevent oxidative damage (Huang et al., 2017). Results showed that both crude extract and glycoside extract obtained from $A$. formosanus cultured in HB medium had strong antioxidant activity with the $\mathrm{IC}_{50}$ values of $248.85 \mu \mathrm{g} / \mathrm{ml}$ and $136.19 \mu \mathrm{g} / \mathrm{ml}$, respectively. This result is in agreement with other studies since glycosides extract has been reported to possess strong antioxidant activity (Wang et al., 2002). In addition, the high antioxidant activity of the crude extract could be due to the presence of high levels of secondary metabolites such as alkaloids, flavoinods, terpenoids, glycosides, and steroids. Evidences showed that such plant components have strong freeradical scavengers and high antimicrobial activity (Jin et al., 2013; Gulzar et al., 2017). The antioxidant activities of these compounds (the inhibition of free radicals, superoxide anions and also inhibition of lipid peroxidation) protecting the human body against oxidative damages have been reported (Wang et al., 2002; Tseng et al., 2006). As a result, the antioxidant activity of $A$. formosanus grown in hydroponic medium (HB) can produce great chemical components as well as antioxidant activity in comparison with many plants such as sweet potato (Ipomoea batatas L.), Gynura bicolor DC., Sanicula lamelligera Hance, Anredera cordifolia (Ten.) Steenis, Solanum nigrum, Asplenium antiquum Makino, Lycium chinense Mill., Saccharum officinarum, Potamogeton pectinatu, Basella alba, Amaranthus mangostanus-green, Amaranthus mangostanus - red, Sechium edule (Jacq.) Swartz - green, Momordica charantia var. abbreviata Ser., and Brassica campestris L. ssp. Chinensis (Chang and Shao, 2006; Chao et al., 2014). Our results suggest that hydroponically cultivated $A$. formosanus can be used as functional food or in medicinal applications.

\section{Conclusions}

This study reported the hydroponic cultivation of A. formosanus for biomass and secondary metabolites production. Among 4 nutrient solutions tested, HB was found to be the most efficient medium for cultivating $A$. formosanus. The extracts of $A$. formosanus in such medium showed potential antioxidant activities due to their high contents of secondary metabolites, especially glycosides. These results provide a new efficient cultivation method to improve the biomass and quality of A. formosanus. The hydroponic-cultivated $A$. formosanus can be a promising source for the pharmaceutical and neutraceutical industries.

\section{References}

Brewer M.S. (2011) Natural antioxidants: sources, compounds, mechanisms of action, and potential applications. Rev. Food Sci. Food Saf. 10: 221-247.

Chang D.C.N., Chou L.C. (2007) Growth responses, enzyme activities, and component changes as influenced by Rhizoctonia orchid mycorrhiza on Anoectochilus formosanus Hayata. Bot. Stud. 48: 445-451.

Chao P.Y., Lin S.Y., Lin K.H., Liu Y.F., Hsu J.I., Yang C.M., Lai J.Y. (2014) Antioxidant activity in extracts of 27 indigenous Taiwanese vegetables. Nutrients 6: 2115-2130.

Cheng S.F., Chang D.C.N. (2009) Growth responses and changes of active components as influenced by elevations and orchid mycorrhizae on Anoectochilus formosanus Hayata. Bot. Stud. 50: 459-466.

Djeridane A., Yousfi M., Nadjemi B., Boutassouna D., Stocker P., Vidal N. (2006) Antioxidant activity of some Algerian medicinal plants extracts containing phenolic compounds. Food Chem. 97: 654-660.

Dong C., Hu D., Fu Y., Wang M., Liu H. (2014) Analysis and optimization of the effect of light and nutrient solution on wheat growth and development using an inverse system model strategy. Comput. Electron. Agric. 109: 221-231.

Du X.M., Sun N.Y., Irino N., Shoyama Y. (2000) Glycosidic constituents from in vitro Anoectochilus formosanus. Chem. Pharm. Bull. 48: 1803-1804. 
Du X.M., Yoshizawa T., Shoyama Y. (1998) Butanoic acid glucoside composition of whole body and in vitro plantlets of Anoectochilus formosanus. Phytochemistry 49: 1925-1928.

Fang H.L., Wu J.B., Lin W.L., Ho H.Y., Lin W.C. (2008) Fur ther studies on the hepatoprotective effects of Anoectochilus formosanus. Phytother. Res. 22: 291-296.

Gulzar S., Nawchoo I.A., Yaqoob U., Hassan A. (2017) A study on variation of phytochemical constituents with altitude and in vitro antimicrobial potential of two species of Ajuga L. Adv. Biomed. Pharm. 4: 19-30.

Han Q., Bing W., Di Y., Hua L., Shi-he L., Yu-hua Z., Xiu-guo H., Yu-gang W., Qi-ming F., Shih-mo Y., Ting-ting T. (2016) Kinsenoside screening with a microfluidic chip attenuates gouty arthritis through inactivating $N F-\kappa B$ signaling in macrophages and protecting endothelial cells. Cell Death Dis. 7: e2350.

Herborne J.B. (1973) Phytochemical methods. London: Chapman and Hall Ltd.

Hsiao H.B., Hsieh C.C., Wu J.B., Lin H., Lin W.C. (2016) Kinsenoside inhibits the inflammatory mediator release in a type-II collagen induced arthritis mouse model by regulating the $T$ cells responses. BMC Complement. Altern. Med. 16: 80.

Huang D.D., Law R.C.S., Mak O.T. (1991) Effects of tissuecultured Anoectochilus formosanus Hay. extracts on the arachidonate metabolism. Bot. Bull. Acad. Sin. 32: 113-119.

Huang M.Y., Lin K.H., Lu C.C., Chen L.R., Hsiung T.C., Chang W.T. (2017) The intensity of blue light-emitting diodes influences the antioxidant properties and sugar content of oyster mushrooms (Lentinus sajor-caju). Sci. Hortic. 218: $8-13$.

Huang Y.C., Chang Y.H., Shao Y.Y. (2006) Effects of genotype and treatment on the antioxidant activity of sweet potato in Taiwan. Food Chem. 98: 529-538.

Jiang J.H., Lee Y.I., Cubeta M.A., Chen L.C. (2015) Characterization and colonization of endomycorrhizal Rhizoctonia fungi in the medicinal herb Anoectochilus formosanus (Orchidaceae). Mycorrhiza 25: 431-445.

Jin C.W., Liu Y., Mao Q.Q., Wang Q., Du S.T. (2013) Mild Fedeficiency improves biomass production and quality of hydroponic-cultivated spinach plants (Spinacia oleracea L.). Food Chem. 138: 2188-2194.

Li D.L., Zheng X.L., Duan L., Deng S.W., Ye W., Wang A.H., Xing F.W. (2017) Ethnobotanical survey of herbal tea plants from the traditional markets in Chaoshan, China. J. Ethnopharmacol. 205: 195-206.

Lin K.H., Huang M.Y., Huang W.D., Hsu M.H., Yang Z.W., Yang C.M. (2013) The effects of red, blue, and white lightemitting diodes on the growth, development, and edible quality of hydroponically grown lettuce (Lactuca sativa $L$. var. capitata). Sci. Hortic. 150: 86-91.

Luo B.F., Du S.T., Lu K.X., Liu W.J., Lin X.Y., Jin C.W. (2012) Iron uptake system mediates nitrate-facilitated cadmium accumulation in tomato (Solanum lycopersicum) plants. J. Exp. Bot. 63: 3127-3136.
Ket N.V., Hahn E.J., Park S.Y., Chakrabarty D., Paek K.Y. (2004) Micropropagation of an endangered orchid Anoectochilus formosanus. Biol. Plant. 48: 339-344.

Ma Z., Li S., Zhang M., Jiang S., Xiao Y. (2010) Light intensity affects growth, photosynthetic capability, and total flavonoid accumulation of Anoectochilus Plants. HortScience 45: 863-867.

Molders K., Quinet M., Decat J., Secco B., Dulière E., Pieters S., Van Der Kooij T., Lutts S., Van Der Straeten D. (2012) Selection and hydroponic growth of potato cultivars for bioregenerative life support systems. Adv. Space Res. 50: $156-165$.

Murashige T., Skoog F. (1962) A revised medium for rapid growth and bioassays with tobacco tissue cultures. Plant Physiol. 15: 473-497.

Ng C.C., Wang C.Y., Wang Y.P., Tzeng W.S., Shyu Y.T. (2011) Lactic acid bacterial fermentation on the production of functional antioxidant herbal Anoectochilus formosanus Hayata. J. Biosci. Bioeng. 111: 289-293.

Parekh J., Chanda S. (2007) In vitro antimicrobial activity and phytochemical analysis of some Indian medicinal plants. Turkish J. Biol. 31: 53-58.

Rehman S.U., Kim I.S., Choi M.S., Luo Z., Yao G., Xue Y., Zhang Y., Yoo H.H. (2015) Evaluation of metabolic stability of kinsenoside, an antidiabetic candidate, in rat and human liver microsomes. Mass Spectrom. Lett. 6: 48-51.

Shafeek M.R., Helmy Y.I., Awatef G.B., Rizk F.A., Omar N.M. (2014) Foliar application of some plant nutritive compounds on growth, yield and fruit quality of hot pepper plants (Capsicum annum, L.) grown under plastic house conditions. Curr. Sci. Int. 3: 1-6.

Shih C.C., Wu Y.W., Lin W.C. (2003) Scavenging of reactive oxygen species and inhibition of the oxidation of low density lipoprotein by the aqueous extraction of Anoectochilus formosanus. Am. J. Chin. Med. 31: 25-36.

Steve A.C., Chidinma O.L., Emmanuella N.E., Chukwuebuka A.K., Sunday A.N., Chidi O.B., Nchedo O.R. (2016) Phytochemical and antimicrobial screening of Cola gigantea leaves, stem and bark. Univ. J. Microbiol. Res. 4: 49-54.

Tseng C.C., Shang H.F., Wang L.F., Su B., Hsu C.C., Kao H.Y., Cheng K.T. (2006) Antitumor and immunostimulating effects of Anoectochilus formosanus Hayata. Phytomedicine 13: 366-370.

Wang S.Y., Kuo Y.H., Chang H.N., Kang P.L., Tsay H.S., Lin K.F., Yang N.S., Shyur L.F. (2002) Profiling and characterization antioxidant activities in Anoectochilus formosanus Hayata. J. Agric. Food Chem. 50: 1859-1865.

Wu R.Z., Baque M.A., Paek K.Y. (2010) Establishment of a large-scale micropropagation system for Anoectochilus formosanus in bioreactors. Acta Hortic. 878: 167-173.

Yadavalli V., Neelam S., Rao A.S., Reddy A.R., Subramanyam R. (2012) Differential degradation of photosystem I subunits under iron deficiency in rice. J. Plant Physiol. 169: 753-759.

Yang L.C., Hsieh C.C., Lu T.J., Lin W.C. (2014) Structurally characterized arabinogalactan from Anoectochilus formo- 
sanus as an immuno-modulator against CT26 colon cancer in $B A L B / c$ mice. Phytomedicine 21: 647-655.

Yang L.C., Lai C.Y., Lin W.C. (2017) Natural killer cell-mediated cytotoxicity is increased by a type II arabinogalactan from Anoectochilus formosanus. Carbohydr. Polym. 155: 466-474.

Yoon Y.J., Murthy H.N., Hahn E.J., Paek K.Y. (2007) Biomass production of Anoectochilus formosanus Hayata in a bioreactor system. J. Plant Biol. 50: 573-576.
Yoshiki Y., Kahara T., Okubo K., Sakabe T., Yamasaki T. (2001) Superoxide-and 1, 1-diphenyl-2-picrylhydrazyl radical-scavenging activities of soyasaponin $\beta$ g related to gallic acid. Biosci. Biotechnol. Biochem. 65: 2162-2165.

Zhang F.S., Lv Y.L., Zhao Y., Guo S.X. (2013) Promoting role of an endophyte on the growth and contents of kinsenosides and flavonoids of Anoectochilus formosanus Hayata, a rare and threatened medicinal Orchidaceae plant. J. Zhejiang Univ. Sci. B 14: 785-792. 